УДК $81 ' 27$

DOI $10.21661 / \mathrm{r}-464693$

\title{
В.Л. Бернштейн
}

\section{ИЗВЛЕЧЕНИЕ ИНФОРМАЦИИ КАК ГЛАВНЫЙ КОМПОНЕНТ ПРОДУКТИВНОГО ЧТЕНИЯ}

Аннотация: в статье проанализированы основные причины, влияющие на успешность формирования у студентов неязыковых вузов умения извлекать информацию из профессиональных текстов. Определено, что для формирования умения понять основной смысл прочитанного необходимо включить в аудиторную работу систематическое обучение неподготовленному чтению, основанное на специальных упражнениях и дополнительном языковом материале.

Ключевые слова: экстенсивное чтение, техника чтения, текст, понимание смысла, навыковая модель, алгоритм развития.

\section{V.L. Bernshteyn}

\section{EXTRACTING INFORMATION AS A MAIN COMPONENT OF PRODUCTIVE READING}

Abstract: the article analyses and provides the reasons for successful development of students' abilities to read professional texts and elicit significant information. It is defined that for the development of the ability to understand the gist of the text it is necessary to include systematic teaching of unprepared reading in the classroom work. The work has to be based on special exercises, classroom practice and additional language material.

Keywords: extensive reading, reading techniques, text, meaning, skill model, development algorithm.

В формировании Иноязычной Коммуникативной Компетенции студента неязыкового вуза важнейшая роль, по нашему мнению, принадлежит развитию умения читать иноязычные тексты, извлекать из них информацию и оперировать 
этой информацией в процессе собственного высказывания в ситуациях аутентичного общения. Конечной целью любого чтения является адекватное понимание прочитанного. Умение читать, простое на первый взгляд умение, по мнению многих преподавателей вуза формируется в школе, поэтому в стенах института его формированию не уделяется должного внимания.

Однако практика преподавания в стенах неязыкового вуза показывает, что у студентов систематически возникает трудность понимания прочитанного текста и, как следствие, невозможность этот текст не только аннотировать или реферировать, но часто даже сформулировать главную идею прочитанного. В большинстве случаев студенты способны механически пересказать текст фразами и предложениями, заимствованными из данного текста один к одному. Этот факт подтверждает мысль о том, что процессы восприятия и понимания текста студентами не протекают одновременно. Их умение читать неполноценно, а технические навыки чтения сформированы на недостаточном уровне. При таком состоянии умения читать процесс извлечения информации является затруднительной пословной дешифровкой текста, не дающей ни информативного, ни эмоционального удовольствия от прочитанного.

Начиная работу в группе студентов над текстами профессиональной направленности и газетными материалами, большинство преподавателей наряду с другими проблемами, связанными с отсутствием понимания прочитанного, отмечают практически полное отсутствие умения прочитать незнакомое слово. И этому можно назвать несколько причин:

- неадекватность существующей в школе методики обучения технике чтения требованиям и целям обучения в вузе;

- недостаточная скорость чтения на иностранном языке: для обеспечения универсальных навыков чтения, его скорость должна быть приближена к скорости чтения на родном языке;

- отсутствие практики чтения незнакомых текстов в аудитории в вузе вообще, что лишает студента возможности получить от преподавателя рекомендации и алгоритм действий; 
- отсутствие специальных заданий по чтению незнакомых текстов для выработки у студента навыков сопоставить, провести аналогии, догадаться о значении незнакомых слов по контексту;

- поверхностное понимание окружающих явлений и информации, ставшее массовым в современном обществе, неспособность увидеть суть происходящего.

Все вышеперечисленное приводит к тому, что студент читает без понимания смысла, который несет в себе текст. То есть, автор текста закодировал свою мысль в системе иностранного языка, а читающий этот текст студент должен понять смысл, раскодировав языковые средства иностранного языка, а это, как правило, является для него непосильной задачей.

Следует отметить, что умение извлекать информацию из текста является комплексным умением. Студент должен знать, что содержание (смысл) текста не является суммой знаний отдельных слов, из которых он состоит, то есть понять текст не эквивалентно понять значения отдельных слов, даже если они выучены, и что для полноценного умения извлекать информацию необходима комплексная подготовка, основанная на методической системе [1].

По мнению таких методистов и исследователей как Н.В. Барышников, обучение чтению в школе рационально строить на навыковой модели умения читать, в которую включены:

- технические навыки чтения;

- рецептивные лексические и грамматические навыки;

- умение антиципации;

- догадка;

- умение сокращать тексты за счет малосущественных деталей;

- навыки пользования и умение рационально использовать справочную литературу в процессе чтения [1, с. 76].

Рассмотрим некоторые эффективные пути, необходимые и возможные в условиях обучения в неязыковом вузе, которые скорректируют умения извлекать информацию при чтении. 
Основой работы в этом направлении является формирование технических навыков неподготовленного чтения, то есть улучшение техники чтения с применением специальных упражнений.

В стенах школы один из самых распространенных методов обучения чтению - метод целых слов, когда обучаемый учится читать слова, предварительно отработанные в устной речи, опираясь на связь между звуковым и графическим образом данного слова. Этот метод хорош для начинающих, но в дальнейшем, он является тормозом в становлении универсальных навыков чтения. Торможение развития заключается в том, что обучаемый получает навык читать только знакомые хорошо отработанные слова и не получает навыка воспринимать печатный текст как некую графическую информацию, основанную на буквеннозвуковых связях. Именно поэтому продолжительная отработка в устной речи только языкового материала базового учебника и предложенного в нем текста, по сути, не развивает умение читать, а наоборот, тормозит развитие данного умения.

По нашему мнению улучшение техники чтения студента возможно лишь при условии включения широкого спектра дополнительных текстов, ориентированных на соответствие в тематике изучаемого языкового материала и общий уровень знания языка студентом в аудиторную работу.

Следует отметить, что в аудитории дополнительной сложностью, с которой сталкивается преподаватель, является то, что студенты читают с различной скоростью и разными способами. Практика преподавания показывает, что в большинстве случаев, студенты настроены на то, что они должны понимать значение каждого слова, а это, в свою очередь, приводит к очень медленному темпу чтения текста и невозможности охватить смысл параграфа и текста в целом.

Одновременно в этой же группе могут быть студенты, которые способны быстро просмотреть текст в поисках основной информации, игнорируя незнакомые слова. Но это те студенты, которых обучили данному способу читать в школе - умению читать незнакомый текст и найти в нем значимую информацию. 
Задачей преподавателя вуза является научить всех студентов читать неподготовленные тексты с осознанием четкой установки: с какой целью они читают текст, какова идея этого текста и его ключевая информация.

Как известно, существуют два основных подхода к чтению:

- экстенсивное (беглое, просмотровое, с целью найти определенную информацию в статье, рекламе, докладе и т. п.);

- интенсивное (тщательное, детальное, с целью понять философские высказывания, грамматические правила, банковские документы и т. п.).

По нашему мнению, оба вида чтения должны быть отражены в аудиторной работе преподавателя и студентов, но особое внимание преподавателя целесообразно уделить экстенсивному чтению, как новому виду учебной деятельности для большинства пришедших в вуз студентов. В любом виде чтения четко сформулированное преподавателем задание должно предварять процесс чтения и это задание должно быть посильным для всех.

Различные подходы к обучению чтению описываются в книге для преподавателей Дж. Скривене (Jim Scrivener) [3, с. 263], где автор предлагает проводить аудиторную работу по следующему алгоритму:

- преподаватель вводит аудиторию в тему предложенного студентам текста;

- предварительная работа (содержащая просматривание заголовка текста и отдельных языковых сложностей), если она требуется;

- постановка преподавателем четкого и ясного всем задания;

- студенты читают текст в установленное время, необходимое для выполнения задания;

- проверка преподавателем выполнения задания (ответы только на заданный вопрос с опорой на текст);

- оценка преподавателем работы студентов (похвала или в случае неудачи совместное обращение к тексту для нахождения ответов); 
- коммуникативное мероприятие, организованное преподавателем на основе полученной информации (обсуждение, дискуссия, комментарии, переход к возможной письменной работе).

На уровне обучения в неязыковом вузе мы считаем необходимым в первую очередь выделить время на выполнение специальных упражнений, ориентированных на развитие скорости чтения студента. По сути, все эти упражнения сводятся к выполнению следующих заданий, которые выполняются в строго лимитированное время:

- определить ключевые слова в абзаце;

- прочитать абзац/ параграф и сформулировать его главную идею;

- найти определенную информацию, например, на странице газеты (среди рекламных объявлений и т. п.);

- найти в статье ответы на 1/2/3 поставленных преподавателем простых и четких вопроса;

- выстроить абзац текста (или короткий текст) из разрозненных предложений на скорость выполнения, в форме соревнования, например.

Данные упражнения, направленные на развитие скорости чтения, являются одновременно и базой для развития умения понять содержание прочитанного, выделить главную информацию, понять структуру текста.

Большое внимание преподавателя также должно быть обращено на развитие рецептивных лексических и грамматических навыков чтения, которые призваны развивать языковое чутье, определять значение новых слов по контексту, по содержащимся в них знакомым элементам. Это могут быть упражнения типа:

- прочитать предложение, определить значение нового слова по знакомым элементам;

- прочитать предложение с незнакомыми словами, образованными от знакомых слов, определить их значение;

- прочитать небольшой текст, определить значение новых слов по сходству с русскими (или латинскими) словами; 
- прочитать небольшой по объему текст, выделить новые слова, определить, что помогло установить их значение;

- прочитать предложения и определить в них группу сказуемого / подлежащего.

Умение антиципации, догадка, также необходимо для умения извлечь информацию и может быть развито с помощью практики. Это могут быть следующие упражнения:

- прочитать предложение и определить значение выделенного слова по контексту;

- дополнить предложения недостающими словами;

- написать свой вариант окончания текста и затем сравнить с оригиналом.

Решающим умением для развития коммуникативных умений, а также умений реферативной деятельности студента, на наш взгляд, является умение компрессировать текст. При небольшом словарном запасе, которым владеют обычно студенты неязыковых вузов, умение выделить главное и отбросить второстепенные детали, осложняющие понимание, требует отдельной систематической подготовки. Это постоянное ориентирование студента на выполнение следующих заданий:

- определение стиля текста и его структуры;

- определение главной мысли каждого абзаца текста;

- определение главного предложения в абзаце;

- определение главной идеи всего текста;

- развитие умения сформулировать главную мысль различными по структуре предложениями;

- развитие умения выразить содержание текста количеством предложений, равным количеству абзацев;

- сформулировать содержание текста 1/2/3 предложениями.

Для определения полноты понимания текста необходима постоянная проверка понимания прочитанного, которая может проводиться с помощью серии 
вопросов, проверяющих понимание студентом текста. Эту проверку понимания смыслов необходимо выстроить в следующей последовательности:

- понимание на уровне ключевого языкового материала;

- понимание на уровне главной идеи и значимой информации;

- понимание на уровне подтекста, если таковой имеется в данном тексте.

Любая работа с текстом становится продуктивнее, если она завершается коммуникативным мероприятием любого вида: дискуссией, ролевыми играми, проблемными заданиями, организованными преподавателем на основе языкового материала и идей прочитанного. Во время коммуникативных мероприятий студент имеет возможность выразить свою точку зрения на полученную информацию, проявить креативность и организаторские способности, а главное, получить практику реальной неподготовленной речи [2].

Организация самостоятельной работы студентов - самостоятельного чтения научно-популярной, научно- технической литературы, а также газетных материалов - необходимый фактор развития умения читать. Решающим условием, определяющим успешность данной работы, является верный подбор интересных источников информации, которые дадут дополнительный импульс и усилят мотивацию читать иноязычную литературу. Следует отметить, что в некоторых вузах проверка самостоятельной работы студента по чтению вынесена на итоговый курсовой экзамен в виде беседы с экзаменатором, чем, на наш взгляд, подчеркнута значимость данного вида деятельности для обучения.

\section{Список литературы}

1. Барышников Н.В. Обучение французскому языку в средней школе: вопросы и ответы. - М.: Просвещение, 1992. - 128 с.

2. Бернштейн В.Л. Обучение неподготовленной иноязычной речи: Методическое пособие для преподавателей английского языка. - М.: МГЭИ, 2004. 164 c.

3. Scrivener J. Learning Teaching Third Edition. - Heinemann, 2011 - 414 p. 
Бернштейн Виктория Левоновна - канд. пед. наук, доцент, доцент кафедры иностранных языков Института бизнеса и делового администрирования ФГБОУ ВО «Российская академия народного хозяйства и государственной службы при Президенте РФ», Россия, Москва.

Bernshteyn Victoria Levonovna - candidate of pedagogical sciences, docent, associate professor of the Department of Foreign Languages at the Institute of Business and Business Administration of the Russian Presidential Academy of National Economy and Public Administration, Russia, Moscow. 